\title{
An Investigation of Chinese Undergraduate English Majors' Graduation Theses from 2007 to 2009
}

\author{
Mei Wu, Assistant Professor \\ Master of Science in Applied Communication Research from College of Communication \\ Boston University, MA, USA \\ $\&$ \\ College of Foreign Languages, Leshan Normal University, China \\ E-mail: wmayline@yahoo.com; wmayline@gmail.com
}

Received: May 21, 2012

Accepted: June 7, 2012

Online Published: June 8, 2012

doi:10.5430/elr.v1n1p97

URL: http://dx.doi.org/10.5430/elr.v1n1p97

This project has been funded by the [Chinese] National Basic Foreign Language Teaching Research Centre (NBFLTRC) for 2012-2013 (project number: JJWYZD2012008).

\begin{abstract}
Data about 459 graduation theses from 2007 to 2009, by undergraduate English majors at a teachers college in Sichuan, were analyzed in SPSS 13.0. The major findings are as follows. Nearly half of the research topics were found to be about English teaching and English acquisition. Studies on literary works center on only a few well-known writers and their representative works. The higher the title of a thesis supervisor's is, the higher score he or she gives to a graduation thesis. Cultural studies are least likely to obtain high scores. Measuring not only students' research and writing skills but also their oral and presentation skills, scores given by an oral defense committee weakly correlate with the scores given by either a supervisor or a reviewer.
\end{abstract}

Keywords: Graduation theses, Undergraduate English majors, Research topics

\section{Introduction}

Graduation Thesis Writing is a required course for undergraduate English majors. This course aims to 1) familiarize students with academic language; 2) introduce the discourse structure of a graduation thesis; and 3) train students' scientific thinking and reasoning skills (Xiong \& Zou, 2011: 5). This course is taught to the third-year students for one semester, before they start writing the graduation thesis in the fourth year of their study at most universities in People's Republic of China.

As a lecturer of Graduation Thesis Writing course, I see a need to investigate data about graduation theses completed by undergraduate English majors at a teachers college in Sichuan from 2007 to 2009, to better instruct students in their writing process.

The English Teaching Syllabus for English Majors, issued by the Chinese Ministry of Education in 2000, states that "Graduation theses should be written in English, and of 3000-5000 words. They should be coherent, clear, substantial, and reflect independent opinions. Grading needs to factor in not only language skills but also independent opinions and innovative ideas of the writing."

Did graduation theses from 2007 to 2009 meet the requirements stated above? What kind fo features do those graduation theses exhibit? This paper will report the results of analyzing information about graduation theses from these three years.

\section{Methodology}

\subsection{Research Questions}

Research Question I. What are the numbers as well as the percentages of the graduation theses for each of the five fields of study, namely, English teaching and acquisition, literature, translation, cultural studies and other studies, from 2007 to 2009 ? 
Research Question II. What are the popular research topics in each field of study?

Research Question III. Supervisors with different titles, such as Professor, Associate Professor and Assistant Professor, gave scores for theses. Is there a statistically significant difference in the mean scores given by the supervisors with different titles? What's the effect of supervisor's titles on thesis scores?

Research Question IV. Is there a statistically significant difference in the mean scores between different research fields, namely, translation, literature, English teaching and English acquisition, and cultural studies? What's the effect of research fields on thesis scores?

Research Question V. A thesis is graded by a supervisor, a reviewer, and an oral defense committee and thus has three scores. The average of these three scores is the final score. How do these four scores correlate with each other?

\subsection{Research Procedures}

Information about the undergraduate graduation theses produced by the English majors at a teachers college in Sichuan from 2007 to 2009 were entered and analyzed in SPSS 13.0. The variables in the data file include:

1) Titles of the undergraduate graduation theses from 2007 to 2009;

2) Three scores that were given by (1) a thesis supervisor (i.e., a teacher who tutors a student in producing the thesis), (2) a reviewer (i.e., a teacher who reads the thesis and judges whether it is ready for oral defense), and (3) an oral defense committee (i.e., a group of three teachers who individually give a score for a student's performance in the oral defense);

3) A final score that is the average of the three scores given by a supervisor, a reviewer and an oral defense committee;

4) The titles of supervisors and reviewers (such as Professor, Associate Professor and Assistant Professor).

Descriptive statistics and inferential statistics were computed to reveal:

1) the numbers as well as percentages of the graduation theses for each field of study;

2) the popular research topics in each field of study;

3) the effect of supervisors' titles on thesis scores;

4) the effect of research fields on thesis scores;

5) the correlation among scores given by a supervisor, a reviewer, an oral defense committee, as well as the final score, which is the average of the three scores mentioned previously.

\section{Results and Discussion}

\subsection{Descriptive Statistics}

Nine hundred and fifty-nine graduation theses were written by undergraduate English majors at a teachers college in Sichuan province, P. R. C. from 2007 to 2009 (332 theses for 2007; 289 theses for 2008 and 338 theses for 2009).

These theses can be loosely classified into five fields of study, in descending order of percentage: studies about English teaching and English acquisition (420 theses, 43.8\%), literature studies (271 theses, 28.3\%), translation studies (132 theses, 13.8\%), cultural studies (68 theses, 7.1\%) and other studies (68 theses, $7.1 \%$ ).

Of all five fields of study mentioned above, topics about English teaching and English acquisition (see Table 1) were most widely written about $(420,43.8 \%)$. This is probably because all these research participants majored in English Education, and they were trained to be English teachers at primary or middle schools upon graduation (though only a small proportion of them eventually became English teachers). Doing a research about English teaching and English acquisition directly relates to these students' future profession.

The next popular fields of study (see Table 1) are literature (271, 28.3\%) and translation (132, 13.8\%). The research participants are overwhelmingly female (more than 90\%), and this is typical of an English Education program in a teachers college, where these young girls are trained to be city or country primary or middle school English teachers. The data show (see table 2) that these young girls are interested in literary works, particularly romantic novels by the Bronte sisters and Jane Austen.

\subsection{Popular Research Topics in Each Field of Study}

The popular research topics for cultural studies include:

1) comparative studies of Chinese culture and Western culture in terms of food (one article for 2008 and two articles 
for 2009), etiquette (two articles for 2009), festivals (two articles for 2007 and one article for 2009) and other things;

2) cultural connotations of English and Chinese words such as color words (three articles for 2007, four articles for 2008 and one article for 2009) or animal words (one article for 2007 and three articles for 2008);

3) cultural education in English teaching (three articles for 2007 and one article for 2008).

The popular research topics for studies about English teaching and English acquisition are about the application of a teaching method, such as cooperative learning, task-based teaching method, or the communicative approach, in teaching a particular English skill.

The studies on literary works center on only a few well-known writers and their representative works. The most popular literary works for thesis writing are included in the following table 2 .

Because the undergraduate English majors are overwhelmingly female, they usually use a female perspective to analyze romantic classics such as Pride and Prejudice, Wuthering Heights, Tess of D'Urbervilles, Jane Eyre, Gone with the Wind, The Scarlet Letter and The Great Gatsby. The students are particularly interested in analyzing the character, destiny, marriage views of the female characters in a literary work, or criticizing the societal or personal reasons for the tragic fate of a female character. This finding is consistent with the results from two empirical studies on graduation thesis topics by Ding Zhangang (2010, 28-29) and Zhang Chunfang (2009, 141-142).

Even though The English Teaching Syllabus for English Majors, issued by the Ministry of Education in 2000, states that "Grading [of graduation theses] needs to factor in not only language skills but also INDEPENDENT OPINIONS and INNOVATIVE IDEAS of the writing," in truth, the repetitive and limited choices of the research topics, particularly in the research field of literature study, exhibit the lack of independent opinions and innovative ideas.

The popular research topics for translation studies are related to the translating of idioms, public signs, menu, animal words or color words, brand names and advertisements, movie titles, and Chinese classics such as $A$ Dream of Red Mansion.

\subsection{The Effect of Supervisors' Titles on Thesis Scores}

There is a statistically significant difference in the mean scores given by the supervisors for year 2008 between supervisors with different titles, as determined by one-way ANOVA $(\mathrm{F}(2,286)=6.621, \mathrm{P}=0.002)$. A LSD post-hoc test revealed that scores given by an Assistant Professor were statistically significantly lower $(76.53 \pm 6.54, \mathrm{P}=0.000)$ than those given by a Professor $(81.17 \pm 6.81, \mathrm{P}=0.000)$, and that scores given by an Associate Professor were statistically significantly lower $(78.09 \pm 8.379, \mathrm{P}=0.032)$ than those given by a Professor $(81.17 \pm 6.81, \mathrm{P}=0.000)$. The effect of supervisors' titles on thesis scores for 2008 is shown in chart 1.

There is also a statistically significant difference in the mean scores given by the supervisors for 2009 between supervisors with different titles, as determined by one-way $\operatorname{ANOVA}(\mathrm{F}(2,335)=9.524, \mathrm{P}=0.000)$. A LSD post-hoc test revealed that scores given by an Assistant Professor were statistically significantly lower $(73.92 \pm 6.19, \mathrm{P}=0.003)$ than those given by an Associate Professor $(76.47 \pm 6.999, \mathrm{P}=0.003)$ and those given by a Professor $(77.69 \pm 7.12$, $\mathrm{P}=0.000$ ). The effect of supervisors' titles on thesis scores for 2009 is also shown in chart 1.

The chart 1 shows that the higher the title of a supervisor's is, the higher score he or she gives to a graduation thesis. Why are the Professors more lenient than the Associate Professors or the Assistant Professors? Could it be that the professors are older and more learned than the younger teachers?

\subsection{The Effect of Research Fields on Thesis Scores}

1) The Effect of Research Fields on Thesis Scores for 2007

There is a statistically significant difference in the mean scores given by the supervisors and the final scores, which are the average of the scores given by a supervisor, a reviewer and an oral defense committee, between different research fields for 2007, as determined by one-way ANOVA $(F(4,327)=2.427, \mathrm{P}=0.048 ; \mathrm{F}(4,327)=3.022, \mathrm{P}=0.018)$. A LSD post-hoc test revealed that scores given by the supervisor for translation in 2007 were statistically significantly higher $(74.81 \pm 7.998, \mathrm{P}=0.006)$ than those for English teaching and English acquisition $(72.34 \pm 6.99, \mathrm{P}=0.025)$ and those for cultural studies $(70.04 \pm 6.109, \mathrm{P}=0.006)$. It's also revealed that scores for literature were statistically significantly higher $(73.7 \pm 8.04, \mathrm{P}=0.038)$ than those for cultural studies $(70.04 \pm 6.109, \mathrm{P}=0.006)$. The four research fields listed in the order of descending scores are: translation, literature, English teaching and English acquisition, and cultural studies.

The same pattern is also revealed by the final scores for 2007 , which averaged the scores given by a supervisor, a reviewer and an oral defense committee. 
The effect of research fields on scores given by supervisors and on the final scores for 2007 is shown in chart 2 .

As shown in chart 2, both the supervisors' scores and the final scores, in descending order, were given for studies on translation, literature, English teaching and English acquisition and finally, cultural studies in 2007.

2) The Effect of Research Fields on Thesis Scores for 2009

There is a statistically significant difference in the mean scores given by a supervisor, a reviewer, an oral defense committee, and the final scores, which are the average scores of the previous scores, between different research fields for 2009 , as determined by one-way ANOVA $(\mathrm{F}(4,333)=2.787, \mathrm{P}=0.027) ; \mathrm{F}(4,333)=5.262, \mathrm{P}=0.000) ; \mathrm{F}(4$, $333)=3.524, \mathrm{P}=0.008 ; \mathrm{F}(4,333)=4.742, \mathrm{P}=0.001)$. A LSD post-hoc test revealed that mean scores given by the supervisor for English teaching and English acquisition in 2009 were statistically significantly higher $(76.41 \pm 6.5$, $\mathrm{P}=0.002)$ than those for literature $(73.81 \pm 6.867, \mathrm{P}=0.002)$. It's also revealed that mean scores given by the reviewer for English teaching and English acquisition in 2009 were statistically significantly higher $(73.65 \pm 7.842, \mathrm{P}=0.007)$ than those for literature $(70.11 \pm 6.916, \mathrm{P}=0.000)$ and those for cultural studies $(68.53 \pm 5.269, \mathrm{P}=0.007)$. In addition, the mean scores given by the reviewer for translation in 2009 were statistically significantly higher $(73.47 \pm 7.503$, $\mathrm{P}=0.017)$ than those for cultural studies $(68.53 \pm 5.269, \mathrm{P}=0.017)$ and those for literature $(70.11 \pm 6.916, \mathrm{P}=0.007)$. The mean final scores, which averaged the scores given by a supervisor, a reviewer and an oral defense committee for 2009, demonstrate a similar pattern. That is, the four research fields listed in the order of descending scores are: English teaching and English acquisition, translation, literature and cultural studies.

The effect of research fields on scores given by supervisors or reviewers and on the final scores for 2009 is shown in chart 3.

As shown in chart 3, the highest scores were given to studies on English teaching and English acquisition, as well as translation, in 2009.

All in all, data from 2007 and 2009 indicate that studies on literature, translation and English teaching and English acquisition are more likely to obtain high scores while cultural studies are least likely to obtain high scores.

Studies on translation and literature were found to be more likely to obtain higher scores, according to statistics in 2007. This is probably because graduation theses on translation and literature serve more interesting reading, for supervisors and reviewers who had to grade dozens of graduation theses for a short period of time during the thesis writing season. The reason why cultural studies are least likely to obtain high scores is probably because they are usually about very broad topics, and therefore, are not likely to be well written.

\subsection{The Correlation of Thesis Scores}

The final scores for graduation theses strongly correlate with the scores given by a supervisor $(\mathrm{R}(330)=.841, \mathrm{P}<0.01$ for 2007; $\mathrm{R}(287)=.696, \mathrm{P}<0.01$ for 2008 ; $\mathrm{R}(336)=.735, \mathrm{P}<0.01$ for 2009$)$, a reviewer $(\mathrm{R}(287)=.775, \mathrm{P}<0.01$ for 2008 ; $\mathrm{R}(336)=.695, \mathrm{P}<0.01$ for 2009), and an oral defense committee $(\mathrm{R}(330)=.787, \mathrm{P}<0.01$ for $2007 ; \mathrm{R}(287)=.76, \mathrm{P}<0.01$ for 2008; $\mathrm{R}(336)=.635, \mathrm{P}<0.01$ for 2009). This is because the final scores for graduation theses were the average scores of the scores given by a supervisor, a reviewer and an oral defense committee.

The scores given by a supervisor moderately correlate with the scores given by a reviewer $(\mathrm{R}(287)=.357, \mathrm{P}<0.01$ for 2008; $\mathrm{R}(336)=.332, \mathrm{P}<0.01$ for 2009). The scores given by a supervisor and a reviewer both measure the written skills and research skills students possess. This explains the moderate correlation between the scores given by a supervisor and a reviewer.

The scores obtained from theses defense weakly correlate with the scores given by a supervisor $(\mathrm{R}(330)=.449$, $\mathrm{P}<0.01$ for 2007; $\mathrm{R}(287)=.26, \mathrm{P}<0.01$ for 2008 ; $\mathrm{R}(336)=.332, \mathrm{P}<0.01$ for 2009). The scores obtained from thesis defense either weakly correlate with the scores given by a reviewer $(\mathrm{R}(287)=.377, \mathrm{P}<0.01$ for 2008$)$, or do not correlate with the scores given by a reviewer (as in 2007 and 2009). The weak correlation between the scores given by an oral defense committee and the scores given by either a supervisor or a reviewer is due to the fact that the scores given by an oral defense committee factored in not only students' research and writing skills but also their oral and presentation skills, which are not indicated by the scores given by a supervisor or a reviewer.

\section{Conclusion}

This investigation of undergraduate English majors' graduation theses from 2007 to 2009 found that nearly half of the research topics are about English teaching and English acquisition. Because the research participants are trained in an English Education program at a teachers college in Sichuan to be English teachers at primary or middle schools upon graduation, doing a research about English teaching and English acquisition most directly relates to these students' future profession. The next popular fields of study are literature and translation. The least popular field of 
study is cultural studies.

The popular research topics for studies about English teaching and English acquisition are about the application of a teaching method, such as cooperative learning, task-based teaching method, or the communicative approach, in teaching a particular English skill. The studies on literary works center on a few well-known writers and their representative works. Students usually use a female perspective to analyze the character, destiny, marriage views of the female characters in a literary work, or to criticize the societal or personal reasons for the tragic fate of a female character. However, the repetitive and limited choices of the research topics exhibit the lack of independent opinions and innovative ideas. The cultural studies are usually comparative studies of Chinese and Western cultures in some aspects.

This investigation also found that the higher the title of a supervisor's is, the higher score he or she gives to a graduation thesis. It's also found that studies on literature, translation and English teaching and English acquisition are more likely to obtain high scores while cultural studies are least likely to obtain high scores.

Because the final scores for graduation theses were the average scores of the scores given by a supervisor, a reviewer and an oral defense committee, these four scores strongly correlate with each other. Because the scores given by a supervisor and a reviewer both measure the written skills and research skills students possess, they moderately correlate with each other. Because the scores given by an oral defense committee factored in not only students' research and writing skills but also their oral and presentation skills, there is a weak correlation between the scores given by an oral defense committee and the scores given by either a supervisor or a reviewer.

The pedagogical implications of this research are that teachers should encourage students to write about diverse research topics encompassing all five research fields, and that students should be encouraged to avoid writing about repetitive or trite topics.

In addition, students need to do studies on literature, translation and English teaching and English acquisition, and to strengthen not only their writing skills but also their research and presentation skills, in order to get high scores for their graduation theses.

\section{References}

Ding, Zhangang. (2010). Practice and Reflections on Mentoring Graduation Theses Writing by Female Undergraduate Students - A Case Study of Graduate Theses by English Majors from China Women's University. Journal of China Women's University, 1, 27-32.

Xiong, Shuhui \& Zou, Weicheng. (2011). Developing Chinese Undergraduate English-Majors' Research Article Writing Competence. Chinese Journal of Applied Linguistics (Quarterly), 3, 5-24.

Zhang, Chunfang. (2009). Researching and Reflections on Quality of Graduation Theses by English Majors in Last Five Years-A Case Study of a University. Journal of Chongqing Jiaotong University (Social Sciences Edition), 2, $141-144$ 
Table 1. Fields of Study for Graduation Theses from 2007 to 2009

\begin{tabular}{|c|c|c|c|c|c|c|c|c|}
\hline \multirow[t]{2}{*}{ Fields of Study } & \multicolumn{2}{|c|}{2007} & \multicolumn{2}{|c|}{2008} & \multicolumn{2}{|c|}{2009} & \multicolumn{2}{|c|}{ Total } \\
\hline & $\mathrm{N}$ & $(\%)$ & $\mathrm{N}$ & $(\%)$ & $\mathrm{N}$ & $(\%)$ & $\mathrm{N}$ & $(\%)$ \\
\hline $\begin{array}{l}\text { English teaching \& } \\
\text { acquisition }\end{array}$ & 166 & $(50.0 \%)$ & 143 & $(49.5 \%)$ & 111 & $(32.8 \%)$ & 420 & $(43.8 \%)$ \\
\hline Literature & 56 & $(16.9 \%)$ & 80 & $(27.7 \%)$ & 135 & $(39.9 \%)$ & 271 & $(28.3 \%)$ \\
\hline Translation & 62 & $(18.7 \%)$ & 25 & $(8.7 \%)$ & 45 & $(13.3 \%)$ & 132 & $(13.8 \%)$ \\
\hline Cultural studies & 26 & $(7.8 \%)$ & 25 & $(8.7 \%)$ & 17 & $(5.0 \%)$ & 68 & $(7.1 \%)$ \\
\hline Others & 22 & $(6.6 \%)$ & 16 & $(5.5 \%)$ & 30 & $(8.9 \%)$ & 68 & $(7.1 \%)$ \\
\hline Total & 332 & $(100 \%)$ & 289 & $(100 \%)$ & 338 & $(100 \%)$ & 959 & $(100 \%)$ \\
\hline
\end{tabular}

Table 2. Number of Articles Written About a Literary Topic from 2007 to 2009

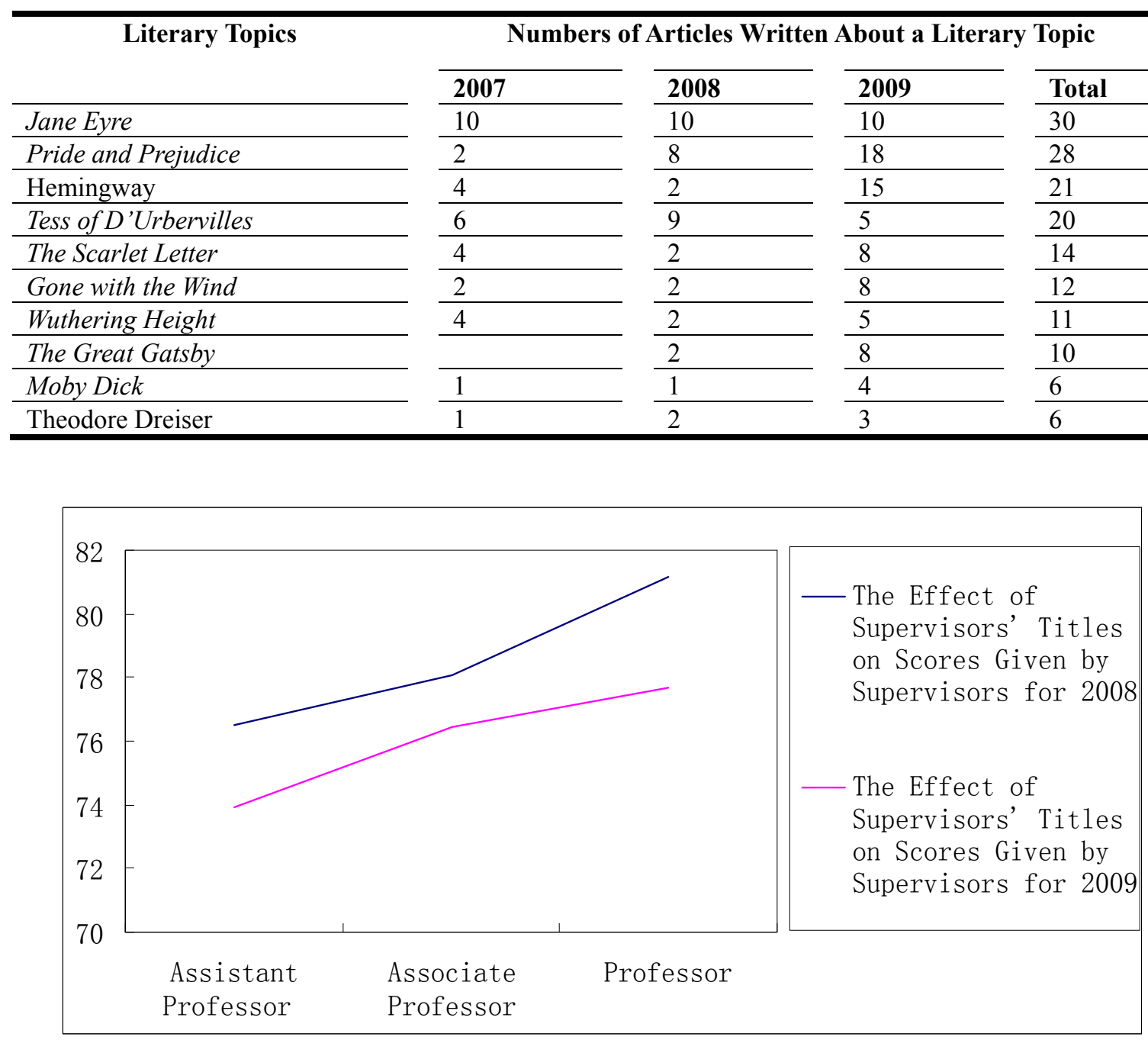

Chart 1. The Effect of Supervisors' Titles on Scores Given by Supervisors for 2008 and 2009 


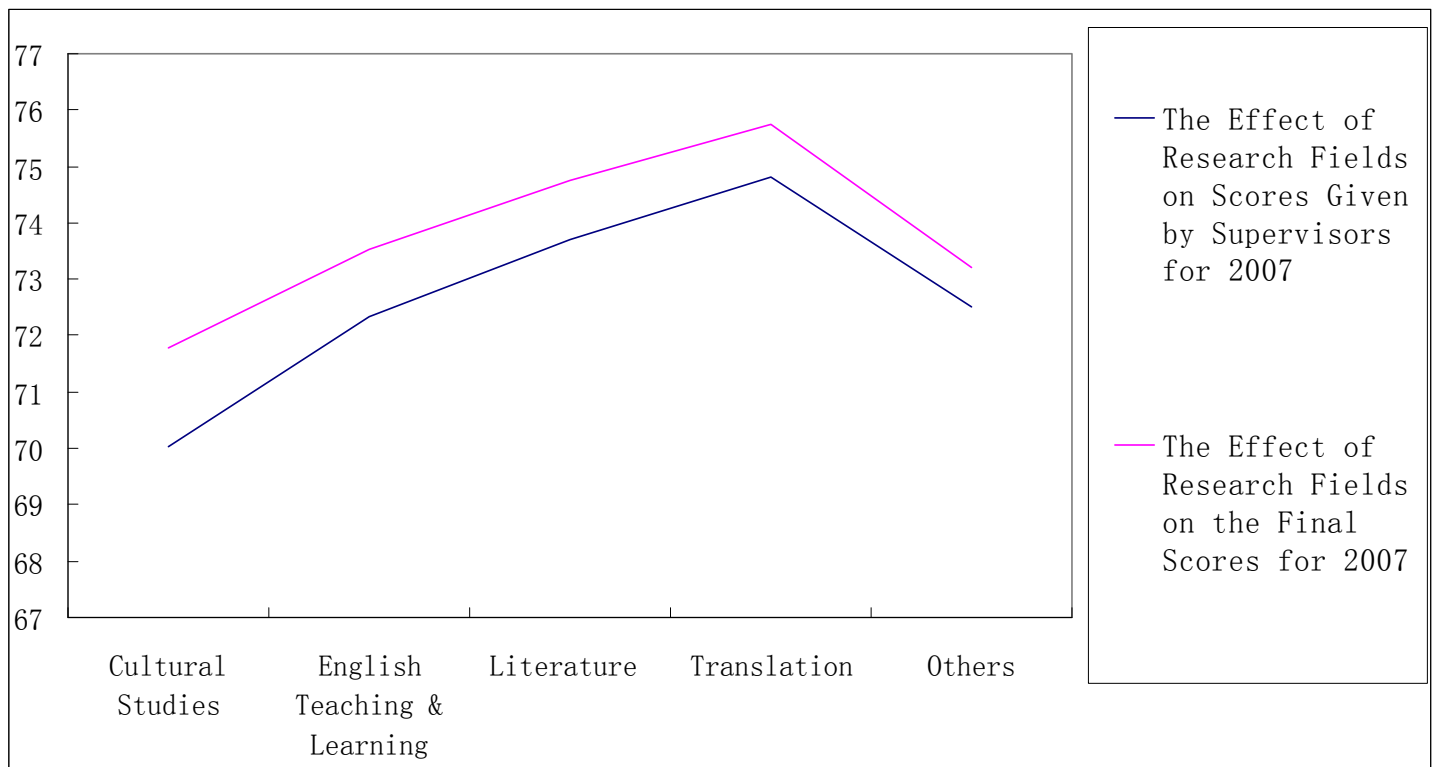

Chart 2. The Effect of Research Fields on Scores Given by Supervisors and on the Final Scores for 2007

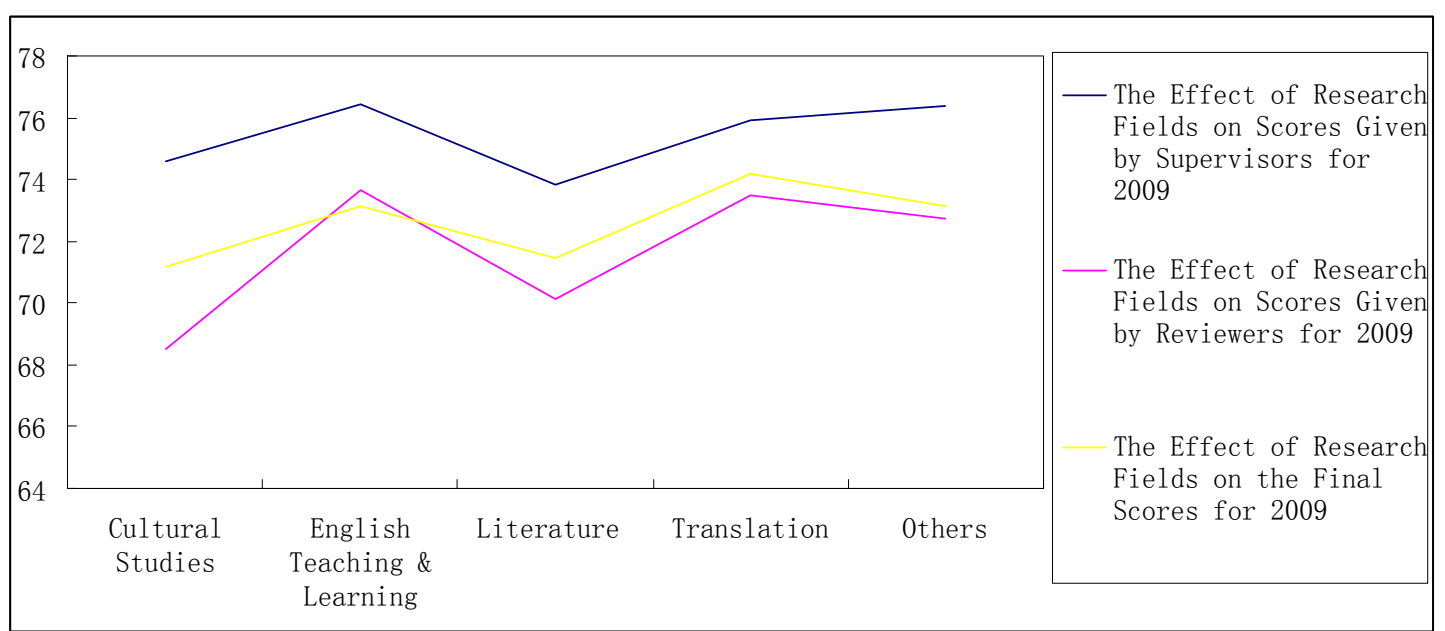

Chart 3. The Effect of Research Fields on Scores Given by Supervisors, Reviewers, and on the Final Scores for 2009 